\title{
Multi-scale Cover Selection by White-tailed Deer, Odocoileus virginianus, in an Agro-forested Landscape
}

\author{
Tim L. HilleR ${ }^{1,2}$, Henry CAMPA III ${ }^{1}$, and ScOtT R. Winterstein ${ }^{1}$ \\ ${ }^{1}$ Department of Fisheries and Wildlife, Michigan State University, 13 Natural Resources Building, East Lansing, Michigan \\ 48824-1222 USA \\ ${ }^{2}$ Current address: School of Natural Resources, University of Nebraska-Lincoln, 3310 Holdrege St., 404 Hardin Hall, Lincoln, \\ Nebraska 68583 USA; Corresponding author e-mail: thiller2@unl.edu
}

Hiller, Tim L., Henry Campa III, and Scott R. Winterstein. 2008. Multi-scale cover selection by White-tailed Deer, Odocoileus virginianus, in an agro-forested landscape. Canadian Field-Naturalist 123(1): 32-43.

Resource selection studies are commonly conducted at a single spatial scale, but this likely does not fully or accurately assess the hierarchical selection process used by animals. We used a multi-spatial scale approach to quantify White-tailed Deer (Odocoileus virginianus) cover selection in south-central Michigan during 2004-2006 by varying definitions of use and availability and ranking the relative importance of cover types under each study design. The number of cover types assigned as selected (proportional use > proportional availability) decreased from coarse (landscape level) to fine (within home range) scales, although at finer scales, selection seemed to be more consistent. Although the relative importance changed substantially across spatial scales, two cover types (conifers, upland deciduous forests) were consistently ranked as the two most important, providing strong evidence of their value to deer in the study area. Testing for resource selection patterns using a multi-spatial scale approach would provide additional insight into the ecology and behavior of a particular species.

Key Words: White-tailed Deer, Odocoileus virginianus, cover selection, selection indices, spatial scale, use-availability, Michigan.

Selectivity, as described by Johnson (1980), relates to an animal's use of some resource (e.g., cover) disproportionately to its availability; this assumes that resources used in a proportion higher than their availability (i.e., "selected") are more important than those resources used in a proportion less than their availability (i.e., "avoided"). Under this premise, highly selected resources should contribute positively to an animal's fitness (Garshelis 2000), with the opposite true for highly avoided resources.

The seemingly simple concepts related to selection, however, can translate into complex issues during studies of resource selection. For example, how availability is defined can impact how selection and avoidance are assigned (Buskirk and Millspaugh 2006). There is a relationship between the spatial extent of availability and the spatial scale of study for the selection process (Otis 1997), and as the defined spatial extent of availability is reduced, selection may become more difficult to detect (McClean et al. 1998; Alldredge and Griswold 2006). Other potential problems include different statistical techniques providing different selection results (Garshelis 2000) and availability defined by non-ecological boundaries (e.g., political boundaries, roads) providing potentially spurious results (Porter and Church 1987; Buskirk and Millspaugh 2006).

Single-scale studies are commonly used to describe resource selection (Thomas and Taylor 2006), although it may be advantageous to consider studying selection at $>1$ spatial scale (Manly et al. 2002). The distribution of most species is not uniform, regardless of the spatial scale of study, due in part to the distribution of food and predators (Stephens and Krebs 1986). These factors suggest that resource selection may best be examined by varying definitions of resource use and availability at different spatial scales (e.g., availability could be defined as proportion of each cover type within a home range or proportion of each cover type within the study area). A multi-scale approach could reveal interesting selection patterns and reduce potential errors associated with human-induced definitions of availability (or use).

By considering the hierarchical selection process used by organisms to meet their habitat requirements (Johnson 1980; Morrison et al. 1992), researchers can make inferences about habitat selection at multiple spatial scales. Using a multi-scale approach, while considering the natural history of an organism, should improve our understanding of the ecology of that organism. For example, within a landscape, what coarsescale features do White-tailed Deer (Odocoileus virginianus) select (e.g., cover types characterizing a home range), and what landscape features (e.g., area of developed land) potentially affect selection? Within the home range, what habitat components do deer select (e.g., within-patch characteristics), and what is the relationship between these components and deer behavior (e.g., selection of adequate thermal refugia)? If we assume that deer generally avoid urbanized areas within a landscape (coarse-scale approach), but deer exist locally in high densities within certain urbanized areas, then what are the differences in resource 
selection, movements, and other behavioral characteristics (e.g., selection of areas closed to hunting) between urban and rural areas?

Our objective was to assess differences in cover selection by adult female White-tailed Deer at multiple spatial scales by varying definitions of resource use and availability. By varying these definitions, for example, spatial patterns of resource selection may emerge to confirm the importance of consistently selected cover types and clarify which cover types may be structurally interchangeable. Because sex- and ageclass resource-selection differences exist for Whitetailed Deer (Main et al. 1996; Kie and Bowyer 1999; Stewart et al. 2003) and deer abundance on our study area was above management goals, the sex-age class of interest for our study was adult female deer.

\section{Study Area}

Our study was conducted in eastern Jackson, western Washtenaw, and southwestern Livingston counties in south-central Lower Michigan (Figure 1). Our studyarea boundary was defined specifically to include all townships containing 1 deer location estimate. The study area ( 8 townships totaling 82636 ha) included publicly and privately owned lands. South-central Michigan has been characterized by a relatively high deer density $\left(\sim 27 / \mathrm{km}^{2}\right.$ during fall 2005 ; Michigan Department of Natural Resources 2005*) and increasing urbanization and other land-use changes. The study area was primarily rural ( $98 \%$ of total land area), but the human population increased $16 \%$ and housing units increased 22\% between 1990 and 2000 (U.S. Census Bureau 2003*). Much of the landscape throughout southern Michigan is expected to experience changing land-use activities (e.g., increasing urbanization) similar to the study area (Madill and Rustem 2001*). Most agriculture in Jackson and Washtenaw counties (total area $=366483 \mathrm{ha})$ was corn (37 $840 \mathrm{ha})$ and soybean (34 $200 \mathrm{ha}$ ) production (Michigan Department of Agriculture $2002 *$ ), with about $52 \%$ of the study area composed of agricultural land use and about $25 \%$ composed of forested land-cover types (Table 1).

Elevation of the study area ranged approximately $180-300 \mathrm{~m}$ and consisted of relatively limited relief (Sommers 1977). During 1971-2000, the average annual snowfall was $99.3 \mathrm{~cm}$, average annual precipitation was $77.9 \mathrm{~cm}$, and mean monthly temperatures ranged from $-5.4^{\circ} \mathrm{C}$ (January) to $21.8^{\circ} \mathrm{C}$ (July) in Jackson County (Midwestern Regional Climate Center, Champaign, Illinois, USA). Our study area had a 150-day growing season (i.e., the average annual accumulation of daily mean temperatures $>5.6^{\circ} \mathrm{C}$ ), generally occurring from 10 May to 7 October (Sommers 1977).

\section{Methods}

\section{Capturing Deer}

We trapped deer during winter (December-March) 2004-2006, using single-door collapsible live traps

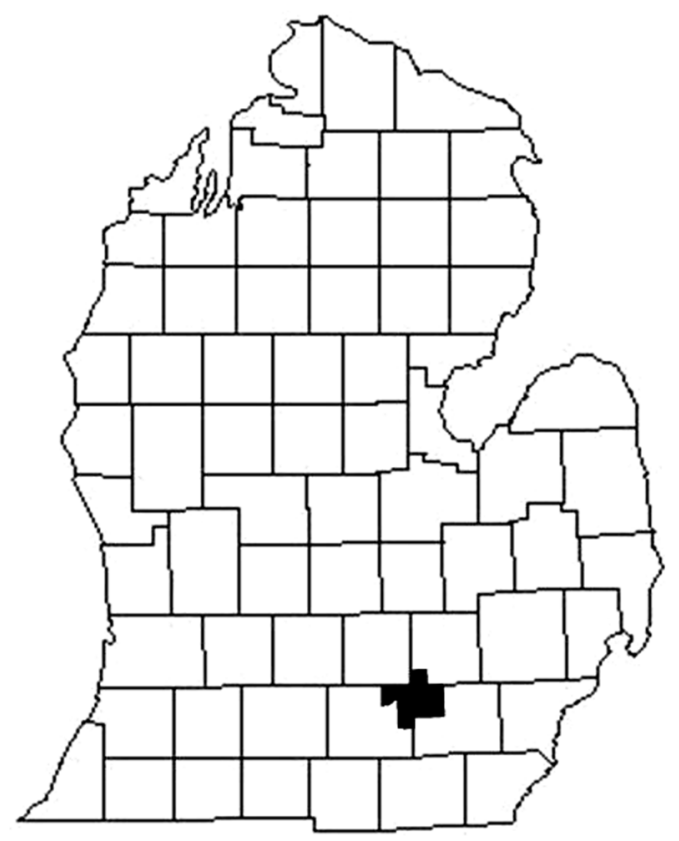

FIGURE 1. Study area (shaded) was defined as townships containing $\geq 1$ deer location estimate, south central Michigan, USA, during 2004-2006.

(Clover 1954). Ages of individuals were estimated through general morphometric differences (e.g., shape and size of head, body size) and dental characteristics (Severinghaus 1949); ages of necropsied individuals later confirmed accuracy of a subset of field observations. We classified deer as fawn $(<1$ year old), yearling ( $\geq 1-<2$ year old), or adult ( $\geq 2$ years old), and reclassified fawns and yearlings on 1 June as they aged, but we used only adult deer for our analyses. Female deer were fitted with metal ear tags (Style 681; National Band and Tag, Newport, Kentucky, USA) and mortality-sensing radio-collars (Model 500; Telonics, Incorporated, Mesa, Arizona, USA; Model G2000; Advanced Telemetry Systems Incorporated, Isanti, Minnesota, USA) with VHF capabilities. The Michigan State University's All-University Committee on Animal Use and Care approved capturing and handling procedures (Application Number 01/04-006-00).

\section{Estimating Locations}

We located all deer 2-5 times/week using triangulation methods (White and Garrott 1990) or from visual observations of known individuals. To increase the potential of our analyses to accurately describe cover selection, deer were located at varying time schedules on a diel basis, with $\geq 1$ nocturnal location/deer/week except during capture periods (Beyer and Haufler 
TABLE 1. Cover-type classification system based on a GIS for study area located in eastern Jackson, western Washtenaw, and southwestern Livingston counties, south central Lower Michigan, USA, during 2004-2006.

\begin{tabular}{llr}
\hline \hline Cover Type & Description & Study Area (\%) \\
\hline Agriculture & Non-vegetated farmland, row crops, forage crops & 52.3 \\
Conifer & Pines (Pinus spp.), other upland conifers & 1.5 \\
Herbaceous openland & Herbaceous vegetation with <25\% woody cover & 2.9 \\
Lowland deciduous forest & $>60 \%$ composed of lowland deciduous tree cover & 8.0 \\
Lowland shrub & Woody shrub cover with >60\% non-water cover & 9.9 \\
Mixed wetland & Floating aquatic vegetation, emergent wetland, mixed non-forest wetland & 3.1 \\
Northern hardwood & $>60 \%$ canopy cover of maple (Acer spp.), beech (Fagus grandifolia), & 2.3 \\
& ash (Fraxinus spp.), cherry (Prunus spp.), birch (Betula spp.) & 1.6 \\
Oak association & $>60 \%$ canopy cover of oak (Quercus spp.) & 11.6 \\
Upland deciduous forest & $>60 \%$ canopy cover of upland deciduous trees & $<0.1$ \\
Upland shrub & $>25 \%$ woody cover & 2.8 \\
Urban & Low and high intensity, roads, parks, golf courses & 3.9 \\
Water & Surface, flowing & 0.1 \\
Other & Aspen (Populus spp.) association, orchards, bare ground & \\
\hline \hline
\end{tabular}

1992). For example, we randomly assigned each deer to 1 of 3 groups, then systematically rotated the groups such that each group would be assigned to a different monitoring time period during each day of monitoring. Azimuths were estimated using a 3-element folding Yagi antenna (Advanced Telemetry Systems, Incorporated, Isanti, Minnesota, USA), portable radio receiver (Model R-1000, Communications Specialists, Incorporated, Orange, California, USA), and mirror-sighting compass. A handheld GPS unit (Model GPS IV; GARMIN International, Incorporated, Olathe, Kansas, USA) was used to estimate the locations for triangulations and for locations of visually observed individuals.

Locations and error ellipses from triangulated data were estimated using the program LOCATE III (Pacer, Truro, Nova Scotia, Canada). We used the maximum likelihood estimator as recommended by White and Garrott (1990) and Nams and Boutin (1991). We followed Nams' (1989) technique to estimate the effectiveness of our sample size to describe selection when telemetry error is large. This method is based on developing a ratio between telemetry error-ellipse size and cover-type patch size.

\section{Cover-type Classification}

We generalized land-use, land-cover data (Michigan Center for Geographic Information 2001*) using ArcView GIS v3.2 software (Environmental System Research Institute, Redlands, California, USA) and Spatial Analyst Extension to define 13 cover types within the study area (Table 1). Our generalization procedures were used to reduce data complexity to reflect our spatial scale of study, but may have excluded certain fine-scale characteristics (e.g., hedgerows, roads) in some instances.

\section{Cover Selection}

We assumed that all location estimates that were classified in the cover type water were inaccurate and we relocated each to the nearest alternative cover type.
However, this adjustment did not preclude the potential importance of water, or more specifically, cover near water, as a resource selected for or avoided by individuals. Cover selection was determined seasonally based on agricultural crop production (i.e., the growing season [150 days; 10 May-7 October], and the non-growing season [215 days; 8 October-9 May]) in the study area. We assumed these 2 time periods approximated seasonal differences in resource availability and deer behaviors (e.g., parturition and primary fawn-rearing versus breeding and fasting). Deer that survived multiple seasons were included in the seasonal data set if they had 30 locations/home range (Seaman et al. 1999), though efforts to collect location data may not have been balanced by season (i.e., less effort during deer capture seasons).

Our approach to assess multi-scale cover selection was to first consider the hierarchal selection process proposed by Johnson (1980). Under this concept, our data described second- (i.e., home range selection within the study area) and third-order (i.e., cover selected within a home range) selection (Table 2) for deer. We then applied study designs 1-3 of Thomas and Taylor (1990) to Johnson's (1980) hierarchal selection process to describe cover selection processes of deer and the magnitude of their differences at different spatial scales. We assumed, for example, that if a cover type dominated the selection process at multiple spatial scales, then its relative importance to deer was higher than a cover type selected at 1 spatial scale. Finally, we applied Ivlev's (1961) electivity index to quantify selection based on these varying definitions of use and availability under Thomas and Taylor (1990).

We used SYSTAT v11 (Systat Software, Inc., San Jose, California, USA) for data analyses and used $95 \%$ confidence limits (CLs; LCL = lower, UCL = upper) to make comparisons. The use of confidence limits is advantageous in that an estimate of effect size and a measure of uncertainty are provided (Johnson 1999). 
TABLE 2. Study designs (and definitions of use and availability used in our study) for collection of use-availability data as described by Thomas and Taylor $(1990,2006)$ and selection hierarchy as defined by Johnson (1980).

\begin{tabular}{|c|c|c|c|}
\hline \multirow[b]{2}{*}{ Study design } & \multicolumn{2}{|c|}{ Scale and Definition } & \multirow[b]{2}{*}{ Selection Hierarchy } \\
\hline & Use & Availability & \\
\hline 1 & $\begin{array}{l}\text { Population-level } \\
\text { (study area) }\end{array}$ & $\begin{array}{l}\text { Population-level } \\
\text { (study area) }\end{array}$ & Second-order \\
\hline 2 & $\begin{array}{l}\text { Individual } \\
\text { (kernel home range) }\end{array}$ & $\begin{array}{l}\text { Population-level } \\
\text { (study area) }\end{array}$ & Second-order \\
\hline 3 & $\begin{array}{l}\text { Individual } \\
\text { (location estimates) }\end{array}$ & $\begin{array}{l}\text { Individual } \\
\text { (kernel home range) }\end{array}$ & Third-order \\
\hline
\end{tabular}

Landscape-scale selection. We used design 1 of Thomas and Taylor (1990) to describe second-order selection (Johnson 1980), where both use and availability are defined at the population level (Table 2). We quantified use and availability using Euclidean distances of location estimates to nearest cover types within the study area. Although this analysis method is most often used for linear or point features, it is equally valid for spatial features such as cover types described as polygons (Conner and Plowman 2001). We pooled all location data (i.e., individuals were not identified) and determined the Euclidean distance between each location to each of the nearest cover types within our classification system. To describe availability, we generated 1000 random points from a uniform distribution bound by the study-area boundary and measured Euclidean distances using methods identical to those used for location estimates.

Meso-scale selection. Use is estimated for each individual while availability for all individuals is identical under design 2 (Thomas and Taylor 1990), which also described second-order selection (Johnson 1980), but under a differing view of use (Table 2). Under this design, we defined availability as the composition of cover types within the study-area boundaries and use as $95 \%$ fixed kernel home ranges. Kernel home ranges were estimated using least-squares cross-validation (Worton 1989; Worton 1995; Seaman et al. 1999) through Animal Movement Extension (Alaska Biological Sciences Center, Glacier Bay, Alaska, USA) in ArcView GIS v3.2 software.

Fine-scale selection. Both use and availability are defined at the individual level with design 3 (Thomas and Taylor 1990), which describes third-order selection by Johnson (1980; Table 2). We defined use as the proportion of location estimates of an individual within each cover type, and availability as the proportional area of each cover type within the $95 \%$ kernel home range of that individual. Design 3 seemed an appropriate measure of availability at finer spatial scales because kernel home ranges may overestimate space used by an animal (i.e., cover types containing no location estimates are often included in a home range estimate; Guthery et al. 2005; Hiller et al. 2009).
Consequently, we developed two methods to characterize availability of cover types within kernel home ranges: conditional and unconditional presence of cover types. Conditional analyses excluded cover types not present within an individual's home range, while unconditional analyses included all cover types within the study area for the estimation of selection indices.

Selection Indices. We used Ivlev's (1961) electivity index to quantify cover selection for each individual and calculated the mean for each cover type by season. This ratio provides an index ranging from -1 (implying avoidance; proportion used < proportion available) to 1 (implying selection; proportion used $>$ proportion available), with 0 (proportion used $=$ proportion available) suggesting random use. Confidence limits for Ivlev's index were truncated at -1 (LCL) or +1 (UCL) when appropriate. We compared selection within and among study designs based on the confidence limits of selection indices (see below) to investigate cover use by deer at multiple spatial scales.

Because point estimates alone may not provide an accurate estimate of resource selection (Hobbs and Bowden 1982), we based selection assignment (i.e., cover types selected, avoided, or randomly used) on confidence limits. Confidence limits were calculated using individuals as the sample unit (data were pooled by season so that an individual deer may have been included in 1 growing or 1 non-growing season). For design 1, confidence limits based on the means and standard errors of Euclidean distances were used to assign selection, but to compare selection with designs 2 and 3, we calculated Ivlev's electivity index based on ratios of mean Euclidean distances. Using mean Euclidean distances as a ratio to assign selection results in mathematical signs opposite (i.e., negative values imply selection) to the results normally obtained with other analytical methods; therefore, we multiplied results of design 1 by -1 to ease comparisons with designs 2 and 3. We followed Strauss (1979) to estimate confidence limits of selection indices under designs 2 and 3.

Ranking Cover Types. Using Ivlev's electivity index, we ranked cover types within a study design and growing season by selection indices (i.e., the cover type 
TABLE 3. Cover selection by White-tailed Deer $(n=20)$ based on Euclidean distances ( $\mathrm{m}$; $95 \%$ confidence limits: LCL $=$ lower, $\mathrm{UCL}=$ upper) between cover types and location estimates or randomly generated points (1000) within the study area, under design $1^{\text {a }}$ of Thomas and Taylor (1990), south-central Michigan, 2004-2006. Location estimates were pooled by agricultural growing season (1626 locations for growing [10 May-7 October], 1867 locations for non-growing season [8 October-9 May]).

\begin{tabular}{|c|c|c|c|c|c|c|c|c|}
\hline \multirow[b]{3}{*}{ Cover type } & & & \multicolumn{6}{|c|}{ Season } \\
\hline & \multicolumn{2}{|c|}{ Random } & \multicolumn{3}{|c|}{ Growing } & \multicolumn{3}{|c|}{ Non-growing } \\
\hline & LCL & $\overline{\mathrm{UCL}}$ & $\overline{\mathrm{LCL}}$ & $\mathrm{UCL}$ & $I^{\mathrm{b}}$ & $\overline{\mathrm{LCL}}$ & UCL & $I$ \\
\hline Agriculture & 137.8 & 175.7 & 402.1 & 440.5 & -0.39 & 320.8 & 351.2 & -0.29 \\
\hline Conifer & 1549.9 & 1720.5 & 487.0 & 554.6 & 0.47 & 454.4 & 515.6 & 0.50 \\
\hline Herbaceous openland & 682.1 & 745.1 & 650.3 & 688.3 & 0.00 & 637.8 & 669.6 & 0.01 \\
\hline Lowland deciduous forest & 357.2 & 395.8 & 353.9 & 381.8 & 0.00 & 371.2 & 394.8 & 0.00 \\
\hline Lowland shrub & 398.4 & 459.3 & 229.0 & 251.7 & 0.23 & 233.7 & 256.5 & 0.22 \\
\hline Mixed wetland & 1321.4 & 1476.1 & 585.9 & 634.8 & 0.35 & 652.6 & 696.3 & 0.31 \\
\hline Northern hardwood & 712.1 & 792.6 & 355.4 & 377.5 & 0.31 & 367.5 & 386.8 & 0.30 \\
\hline Oak association & 839.3 & 918.3 & 513.0 & 544.4 & 0.21 & 505.7 & 534.5 & 0.22 \\
\hline Upland deciduous forest & 355.7 & 402.8 & 122.6 & 138.3 & 0.44 & 133.7 & 148.6 & 0.41 \\
\hline Upland shrub & 10914.0 & 11497.3 & 13502.5 & 13726.0 & -0.08 & 13167.8 & 13367.3 & -0.07 \\
\hline Urban & 1241.0 & 1349.1 & 1870.1 & 1995.4 & -0.16 & 2000.7 & 2108.3 & -0.19 \\
\hline Water & 1726.8 & 1905.9 & 870.1 & 953.1 & 0.29 & 1007.6 & 1077.5 & 0.23 \\
\hline Other & 4192.0 & 4489.5 & 3807.9 & 4014.1 & 0.22 & 3574.2 & 3768.1 & 0.05 \\
\hline
\end{tabular}

${ }^{a}$ Design 1 identifies population-level use and population-level availability. Individuals are not identified.

bSelection indices based on Ivlev's (1961) electivity index using mean distance of random points (availability) and used points (use). If 95\% CLs overlapped, $I=0.00$; if CLs of random points $>$ CLs of used points, $I$ was calculated using LCL of random and UCL of used ( $I>0$, implying selection); if CLs of random points < CLs of used points, $I$ was calculated using LCL of used and UCL of random $(I<0$, implying avoidance). Index was multiplied by -1 to standardize direction of selection $(+)$ and avoidance $(-)$ with other study designs.

with the highest selection index within a set received a rank of 1 , and so on). Cover types with identical selection indices within a design and season were assigned identical ranks. To assess overall relative importance, we assigned the average $\operatorname{rank}\left(\bar{R}_{i}\right)$ among study designs for each cover type $\bar{R}_{i}$ within a season based on the equation

$$
\begin{aligned}
& \bar{R}_{i}=[\text { design } 1+\text { design } 2+(0.5 \times \text { design } 3 \mathrm{U}) \\
& +(0.5 \times \text { design } 3 \mathrm{C}] / 3,
\end{aligned}
$$

which incorporated the weighted average of the two design 3 methods ( $\mathrm{U}=$ unconditional, $\mathrm{C}=$ conditional). Ranking of cover types among designs were ordered from the lowest $\bar{R}_{i}$ (assigned the rank of 1) to the highest $\bar{R}_{i}$ (assigned the highest rank value within the set of cover types). Cover types with identical values of $\bar{R}_{i}$ were assigned the same rank.

\section{Results}

We captured and radiomarked a total of 42 female deer during our study. A subset of 20 radiomarked adult deer (i.e., captured as adult or that aged into adult during our study) was available for analysis (i.e., individuals with $\geq 30$ locations; Seaman et al. 1999). This subset contained a total of 3493 location estimates (growing season $=1626$ locations, non-growing season $=$ 1867 locations) and a mean of 71 locations/seasonal home range over both seasons (3493 locations divided by 49 seasonal home ranges from 20 deer). We pooled data by year for each season due to small sample sizes. The growing seasons of 2004, 2005, and 2006 included 7, 14, and 3 deer, respectively. The non-growing seasons of 2004, 2005, and 2006 included 7, 11, and 7, deer, respectively. Five deer were included more than once in one of the two seasons, so individual totals for each season (24 sets of locations for the growing season, 25 sets of locations for the non-growing season) exceeded the total number of deer $(n=20)$ available for analyses.

Using generalization procedures in a GIS and our cover-type classification system, the patch size of cover types on our study area ranged from $<1$ ha to $>11000$ ha (e.g., an agricultural matrix) with a mean size of 29.2 ha $(94 \%$ of patches were $<40$ ha). For sample size assessment, we estimated a mean telemetry error-ellipse size of 10.2 ha and a mean landscapepatch size of $29.2 \mathrm{ha} /$ patch on our study area, resulting in an ellipse-to-patch diameter ratio of 0.59 . This ratio suggested that the appropriate sample size should be twice the normally desired sample size to describe cover use while minimizing bias (see Nams 1989: Figure 3 ). Because we used only individuals with $\geq 30$ locations (Seaman et al. 1999), but obtained $2.4 \times$ that value (i.e., $\bar{x}=71$ locations/deer/home range; range $=$ 30-133), we considered our telemetry data to contain minimal bias for describing cover selection regardless of our assessment method. 


\section{Cover Selection}

Landscape-scale selection. Under design 1, selection was assigned for 8 and 9 cover types for the growing and non-growing seasons, respectively (Table 3). Selection indices for both seasons ranked conifers and upland deciduous forests as the most highly selected (each $I>0.40$ ), while agriculture was the most highly avoided cover type. Although indices differed somewhat between seasons, the patterns of selection were similar when assessed under this design (Table 4). Two cover types moved one rank value (lowland deciduous forest, other), while one cover type (oak association) moved from a rank of 8 during the growing season to a rank of 6 during the non-growing season. All other cover types were ranked consistently between seasons, suggesting no change in relative selection under this study design.

Meso-scale selection. The cover types upland shrub and other were absent (i.e., received no use) from kernel home ranges under design 2; consequently, we considered both as highly avoided cover types during both seasons (Table 5). Urban areas were the most highly avoided, but used (i.e., contained locations), cover type during both seasons. Under design 2, we assigned fewer cover types as selected (i.e., based on our definition of selection) in comparison to design 1. Conifers were highly selected, while lowland shrub and upland deciduous forest were moderately selected, with similar selection indices for all three cover types during both seasons. Ranking of cover types by season was similar under design 2 (Table 4). Herbaceous openlands and water each changed in their relative importance between seasons by a value of two; herbaceous openlands became more important and water less important during the non-growing season. Although locations estimated to be in water were moved to the nearest alternative cover type, water was often included within kernel home-range boundaries.

Fine-scale selection. Unconditional analysis under design 3 assigned relatively low values for selection to one cover type during each season (upland deciduous forests for growing, conifers for non-growing; Table 6). All other cover types using unconditional analysis were randomly used. The relative importance of cover types changed substantially between seasons (Table 4). Herbaceous openland, mixed wetland, and urban greatly decreased in importance (i.e., rank decreased 4) during the non-growing season; lowland shrub, oak association, and northern hardwood increased in importance (i.e., rank increased 3) during the non-growing season.

Similarly, conditional analysis under design 3, selection included only one cover type during each season, upland deciduous forests during the growing season and conifers during the non-growing season; all other cover types were used randomly (Table 7). The dif- ference in relative importance between seasons (growing versus non-growing) was greatest for urban (rank decreased by nine) and oak association (rank increased by seven). Moderate differences in importance included mixed wetland (rank decreased by four), herbaceous openland (rank decreased by three), lowland shrub (rank increased by three), and northern hardwood (rank increased by three); all other cover types had a difference in rank of 2 (Table 3 ).

Ranking Cover Types. Using our equation to estimate the mean rank among the study designs, most (77\%) cover types had a similar rank between seasons (i.e., rank changed 1; Table 4). During the growing season, mixed wetland increased in relative importance by three and urban increased in relative importance by two, while oak association decreased in relative importance by three. Conifers and upland deciduous forests were the two most important cover types irrespective of season, while agriculture, other, upland shrub, and urban generally were of low relative importance as cover. Although use and availability of water were somewhat inconsistently defined among study designs, the number of locations in water that were moved to the nearest adjacent cover type was $<0.04 \%$ of all locations.

\section{Discussion}

How humans perceive resource availability could be different from how the species under study perceives availability (Litvaitis et al. 1996), which should increase our skepticism of single-scale studies in many instances. If resource selection patterns emerge over multiple spatial scales, it would be logical to assume strong evidence exists for selection of certain resources. Conversely, depending on study objectives, we may question the results of some studies conducted at a single spatial scale, especially if that scale seems to contradict selection patterns based on empirical evidence. For deer, the distribution of hunters and effects of snow and harsh weather may also confound comparisons of cover selection among studies.

The use of Johnson's (1980) system of ranking has been implemented in several ungulate studies. Lopez et al. (2004) used a multi-scale process (first-, second-, and third-order selection) to examine habitat use by Florida Key Deer (O. v. clavium) in an increasingly urban environment; they found that Key Deer generally selected for upland vegetation types regardless of spatial scale, and hypothesized that uplands provided preferred foods, cover, and freshwater. In Oregon, the relative importance of 11 plant communities ranked and compared seasonally based on the feeding activities of Mule Deer ( $O$. hemionus; individual animals were not identified) and the relative importance of each plant community varied substantially by season (Bodurtha et al. 1989: Table 2). These examples provide evidence that resource selection studies 
TABLE 4. Relative importance of cover types by adult female White-tailed Deer $(n=20)$ based on selection indices under multiple study designs (see Thomas and Taylor [1990]), south central Michigan, 2004-2006. Data were pooled by agricultural growing season (growing [10 May-7 October], non-growing [8 October-9 May]).

\begin{tabular}{|c|c|c|c|c|c|}
\hline \multirow{2}{*}{$\begin{array}{l}\text { Season } \\
\text { Cover type }\end{array}$} & \multicolumn{4}{|c|}{ Study Design $^{\mathrm{a}}$} & \multirow[t]{2}{*}{ Relative Importance $^{\mathrm{d}}$} \\
\hline & 1 & 2 & $3 \mathrm{U}^{\mathrm{b}}$ & $3 \mathrm{C}^{\mathrm{c}}$ & \\
\hline \multicolumn{6}{|l|}{ Growing } \\
\hline Agriculture & 13 & 9 & 7 & 7 & 11 \\
\hline Conifer & 1 & 1 & 2 & 3 & 1 \\
\hline Herbaceous openland & 9 & 10 & 5 & 6 & 8 \\
\hline Lowland deciduous forest & 9 & 6 & 3 & 4 & 6 \\
\hline Lowland shrub & 6 & 3 & 7 & 8 & 4 \\
\hline Mixed wetland & 3 & 7 & 3 & 4 & 3 \\
\hline Northern hardwood & 4 & 4 & 10 & 10 & 5 \\
\hline Oak association & 8 & 5 & 9 & 9 & 7 \\
\hline Upland deciduous forest & 2 & 2 & 1 & 2 & 2 \\
\hline Upland shrub & 11 & 12 & 11 & 11 & 13 \\
\hline Urban & 12 & 11 & 5 & 1 & 10 \\
\hline Water & 5 & 8 & 11 & 12 & 8 \\
\hline Other & 7 & 12 & 11 & 12 & 12 \\
\hline \multicolumn{6}{|l|}{ Non-growing } \\
\hline Agriculture & 13 & 9 & 6 & 6 & 10 \\
\hline Conifer & 1 & 1 & 1 & 1 & 1 \\
\hline Herbaceous openland & 9 & 8 & 9 & 9 & 9 \\
\hline Lowland deciduous forest & 10 & 6 & 3 & 4 & 7 \\
\hline Lowland shrub & 6 & 3 & 3 & 5 & 3 \\
\hline Mixed wetland & 3 & 7 & 8 & 8 & 6 \\
\hline Northern hardwood & 4 & 4 & 7 & 7 & 5 \\
\hline Oak association & 6 & 5 & 5 & 2 & 4 \\
\hline Upland deciduous forest & 2 & 2 & 2 & 2 & 2 \\
\hline Upland shrub & 11 & 12 & 10 & 10 & 12 \\
\hline Urban & 12 & 11 & 10 & 10 & 12 \\
\hline Water & 5 & 10 & 10 & 10 & 8 \\
\hline Other & 8 & 12 & 10 & 10 & 11 \\
\hline
\end{tabular}

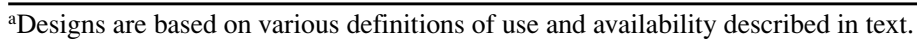

${ }^{b}$ Unconditional analyses included all cover types within the study area for describing selection.

'Conditional analyses excluded cover types not present within an individual's home range.

${ }^{\mathrm{d}}$ Relative importance $\left(\bar{R}_{i}\right)=[$ design $1+$ design $2+(0.5 \times$ design $3 \mathrm{U})+(0.5 \times \operatorname{design} 3 \mathrm{C}] / 3$.

should consider the selection behaviors and natural history of the species of interest. Failure to do so may provide an incomplete understanding of selection processes.

Under the hierarchical selection process, selection at finer scales is dependent on selection at more coarse scales (Johnson 1980), so we would expect selection indices to change based on what we defined as available to individuals or groups of individuals. To illustrate, third-order selection (e.g., the selection of conifers as thermal cover within a home range) is dependent on second-order selection (e.g., the selection of conifers across a landscape). If conifers exist within a home range, but there are no locations within the conifers, we might conclude that conifers were avoided. However, if the proportion of conifers within the home range exceeded the proportion of conifers within the study area, selection is implied. Regardless of the outcome, Johnson's (1980) hierarchical selection process provides a basis from which to study these patterns of selection.
Our analyses showed strong patterns of selection regardless of spatial scale, but there were also some inconsistencies among certain cover types based on changes in their relative importance across multiple spatial scales. Conifers and upland deciduous forests were ranked as the two most important cover types on our study area regardless of the spatial (i.e., study design) or temporal (i.e., season) scale studied. Several cover types changed their relative importance across spatial scales. For example, during the growing season, urban areas shifted from relatively unimportant at the landscape scale to increasingly important as a habitat component within home ranges. Deer near urban areas may have utilized them as fawning cover, although this is based on conjecture.

\section{Single-scale Studies}

We based our interpretation of selection patterns on past research, but White-tailed Deer habitat is diverse across their geographic distribution, making comparisons somewhat difficult, especially as spatial scale 
TABlE 5. Cover selection by adult female White-tailed Deer $(n=20)$ under design $2^{\text {a }}$ of Thomas and Taylor (1990), south central Michigan, 2004-2006. Data were pooled by agricultural growing season (150 days; 10 May-7 October; 23 home ranges during growing season, 25 home ranges during non-growing season) within an agro-forested landscape.

\begin{tabular}{|c|c|c|c|c|c|c|c|}
\hline \multirow{2}{*}{$\begin{array}{l}\text { Seaso } \\
\text { Cover type }\end{array}$} & \multirow{2}{*}{$\begin{array}{l}\text { esence in home } \\
\text { range }(p)\end{array}$} & \multicolumn{2}{|c|}{ Proportional use } & \multicolumn{4}{|c|}{ Selection index ${ }^{b}$} \\
\hline & & $p$ & $\operatorname{SE}(p)$ & $I$ & $\mathrm{LCL}^{\mathrm{c}}$ & UCL & $\mathrm{Use}^{\mathrm{d}}$ \\
\hline \multicolumn{8}{|l|}{ Growing } \\
\hline Agriculture & 0.74 & 0.164 & 0.047 & -0.52 & -0.53 & -0.51 & - \\
\hline Conifer & 0.65 & 0.154 & 0.057 & 0.81 & 0.31 & 1.00 & + \\
\hline Herbaceous openland & 0.22 & 0.009 & 0.007 & -0.53 & -1.00 & 0.17 & o \\
\hline Lowland deciduous forest & 0.74 & 0.078 & 0.024 & -0.02 & -0.26 & 0.22 & o \\
\hline Lowland shrub & 0.83 & 0.204 & 0.038 & 0.35 & 0.21 & 0.48 & + \\
\hline Mixed wetland & 0.48 & 0.022 & 0.013 & -0.17 & -1.00 & 0.82 & o \\
\hline Northern hardwood & 0.74 & 0.045 & 0.012 & 0.33 & -1.00 & 1.00 & o \\
\hline Oak association & 0.57 & 0.019 & 0.007 & 0.10 & -1.00 & 1.00 & o \\
\hline Upland deciduous forest & 0.96 & 0.288 & 0.044 & 0.43 & 0.33 & 0.52 & + \\
\hline Upland shrub & 0.00 & 0.000 & & -1.00 & & & - \\
\hline Urban & 0.09 & 0.002 & 0.001 & -0.87 & -1.00 & -0.67 & - \\
\hline Water & 0.48 & 0.015 & 0.005 & -0.44 & -0.99 & 0.11 & o \\
\hline Other & 0.00 & 0.000 & & -1.00 & & & - \\
\hline \multicolumn{8}{|l|}{ Non-growing } \\
\hline Agriculture & 0.88 & 0.172 & 0.033 & -0.50 & -0.51 & -0.49 & - \\
\hline Conifer & 0.84 & 0.162 & 0.051 & 0.83 & 0.35 & 1.00 & + \\
\hline Herbaceous openland & 0.40 & 0.012 & 0.006 & -0.42 & -1.00 & 0.44 & o \\
\hline Lowland deciduous forest & 0.80 & 0.072 & 0.019 & -0.06 & -0.29 & 0.19 & o \\
\hline Lowland shrub & 0.84 & 0.205 & 0.039 & 0.35 & 0.21 & 0.49 & + \\
\hline Mixed wetland & 0.60 & 0.027 & 0.011 & -0.07 & -1.00 & 0.95 & o \\
\hline Northern hardwood & 0.84 & 0.033 & 0.009 & 0.18 & -1.00 & 1.00 & o \\
\hline Oak association & 0.72 & 0.022 & 0.007 & 0.17 & -1.00 & 1.00 & o \\
\hline Upland deciduous forest & 1.00 & 0.282 & 0.035 & 0.42 & 0.32 & 0.51 & + \\
\hline Upland shrub & 0.00 & 0.000 & & -1.00 & & & - \\
\hline Urban & 0.08 & 0.001 & 0.001 & -0.93 & -1.00 & -0.84 & - \\
\hline Water & 0.40 & 0.012 & 0.004 & -0.53 & -1.00 & -0.05 & - \\
\hline Other & 0.00 & 0.000 & & -1.00 & & & - \\
\hline
\end{tabular}

aDesign 2 use was based on cover types bounded by 95\% fixed kernel home ranges; availability was based on cover types bounded by the study area.

'Selection indices based on Ivlev's (1961) electivity index (I).

${ }^{\mathrm{c} C o n f i d e n c e ~ l i m i t s ~}(95 \%)$ were truncated at -1 and 1 , and could not be estimated if proportional use $=0$.

If $95 \% \mathrm{CLs}>0$, selection (+) was assigned; if 95\% CLs $<0$, avoidance (-) was assigned; and if 95\% CLs included 0, random use (o) was assigned.

decreases. Harvest management strategies that affect hunting pressure and distribution of hunters may affect the distribution of deer (Harden et al. 2005) and, therefore, the cover selection process that they use. Comparisons along a latitudinal gradient may also be difficult, as weather conditions dictate the vegetation structure used as thermal refugia by deer during harsh conditions. Also, cover-type classifications are not consistent among studies (e.g., use of classification systems specific to individual states or provinces versus National Hierarchical Framework of Ecological Units), further increasing the difficulty of comparisons, especially across the geographic distribution of the Whitetailed Deer.

In Arkansas, Miranda and Porter (2003: table 1) used two general habitat suitability classes (food and cover) to model landscape-scale habitat suitability based on cover types, though cover on their study area might have been utilized by deer for security more so than thermal refugia during winter due to milder winter weather conditions. The suitability of shrublands, deciduous forests, low-intensity residential, and woody wetlands on their study area was high for both food and cover, whereas evergreen forests served primarily as cover, and grassland-herbaceous and agricultural cover types served primarily as food. Water, highintensity residential, and various other cover types were generally considered unsuitable. Although we found lowland shrubs to be relatively important during the non-growing season, this cover type was not as important on our study area as suggested by Miranda and Porter (2003), perhaps due to differences in species composition between areas. Conifers (e.g., Eastern Redcedar [Juniperus virginiana]) on our study area may have contributed cover and some winter food value (see Bender and Haufler 1994) based 
TABLE 6. Cover selection by adult female White-tailed Deer $\left(n=20\right.$; design $3^{\text {a }}$ of Thomas and Taylor [1990]) pooled by agricultural growing season (150 days; 10 May-7 October; 23 home ranges during growing season, 25 home ranges during non-growing season) in an agro-forested landscape in south-central Michigan, 2004-2006. Proportional use and selection indices were unconditional on presence of cover types within home ranges.

\begin{tabular}{|c|c|c|c|c|c|c|}
\hline \multirow{2}{*}{$\begin{array}{l}\text { Season } \\
\text { Cover type }\end{array}$} & \multicolumn{2}{|c|}{ Proportional use } & \multicolumn{4}{|c|}{ Selection index ${ }^{b}$} \\
\hline & $p$ & $\mathrm{SE}(p)$ & $I$ & $\mathrm{LCL}^{\mathrm{c}}$ & UCL & $\mathrm{Use}^{\mathrm{d}}$ \\
\hline \multicolumn{7}{|l|}{ Growing } \\
\hline Agriculture & 0.154 & 0.046 & -0.03 & -0.12 & 0.05 & o \\
\hline Conifer & 0.168 & 0.063 & 0.04 & -0.05 & 0.14 & o \\
\hline Herbaceous openland & 0.009 & 0.008 & 0.00 & -1.00 & 1.00 & o \\
\hline Lowland deciduous forest & 0.081 & 0.026 & 0.02 & -0.23 & 0.27 & o \\
\hline Lowland shrub & 0.191 & 0.041 & -0.03 & -0.10 & 0.03 & o \\
\hline Mixed wetland & 0.023 & 0.015 & 0.02 & -1.00 & 1.00 & o \\
\hline Northern hardwood & 0.030 & 0.009 & -0.20 & -0.76 & 0.36 & o \\
\hline Oak association & 0.016 & 0.006 & -0.09 & -1.00 & 1.00 & o \\
\hline Upland deciduous forest & 0.325 & 0.057 & 0.06 & 0.02 & 0.10 & + \\
\hline Upland shrub & 0.000 & & & & & \\
\hline Urban & 0.002 & 0.002 & 0.00 & -1.00 & 1.00 & o \\
\hline Water & 0.000 & & & & & \\
\hline Other & 0.000 & & & & & \\
\hline \multicolumn{7}{|l|}{ Non-growing } \\
\hline Agriculture & 0.162 & 0.038 & -0.03 & -0.11 & 0.05 & o \\
\hline Conifer & 0.192 & 0.058 & 0.08 & 0.01 & 0.17 & + \\
\hline Herbaceous openland & 0.005 & 0.004 & -0.41 & -1.00 & 1.00 & o \\
\hline Lowland deciduous forest & 0.074 & 0.025 & 0.01 & -0.27 & 0.30 & o \\
\hline Lowland shrub & 0.206 & 0.042 & 0.01 & -0.06 & 0.06 & o \\
\hline Mixed wetland & 0.018 & 0.009 & -0.20 & -1.00 & 1.00 & o \\
\hline Northern hardwood & 0.026 & 0.012 & -0.11 & -1.00 & 0.80 & o \\
\hline Oak association & 0.022 & 0.011 & 0.00 & -1.00 & 1.00 & o \\
\hline Upland deciduous forest & 0.294 & 0.046 & 0.02 & -0.02 & 0.06 & o \\
\hline Upland shrub & 0.000 & & & & & \\
\hline Urban & 0.001 & & & & & \\
\hline Water & 0.000 & & & & & \\
\hline Other & 0.000 & & & & & \\
\hline
\end{tabular}

a Design 3 use was based on proportion of locations in each cover type averaged over individuals; availability was based on mean proportion of area of cover types bounded by individual $95 \%$ fixed kernel home range by season. Cover types absent from a home range had proportional availability $=0$.

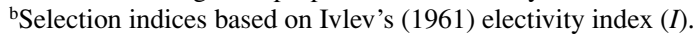

${ }^{\mathrm{c}}$ Confidence limits $(95 \%)$ were truncated at -1 and 1 , and could not be estimated if proportional use $=0$.

${ }^{\mathrm{d}}$ If $95 \% \mathrm{CLs}>0$, selection (+) was assigned; if 95\% CLs <0, avoidance (-) was assigned; and if 95\% CLs included 0, random use (o) was assigned.

on their relative importance (Table 4); the importance of upland deciduous forests (food and cover) on our study area seemed consistent with Miranda and Porter (2003) at the landscape level.

In Midwestern agricultural areas, White-tailed Deer utilize agricultural crops throughout the year (Gladfelter 1984). Regardless of season, we found that agricultural areas increased in relative importance as spatial scale decreased (i.e., scale of selection became finer). This suggests that agricultural areas were much less important to deer at the landscape scale in comparison to providing a habitat component (food) within deer home ranges. This may explain why crop damage by deer seemed to be localized near field edges bordered by cover, at least for relatively large fields; smaller fields may have crop damage throughout (K. Bissell, Michigan Department of Natural Resources, personal communication; Braun 1996). Approximately half of the study area was composed of agricultural areas, which was probably at a much higher proportion than to provide optimal conditions for White-tailed Deer (Hiller et al. 2009).

\section{Issues of Scale}

Cover selection by deer on our study area showed scale effects. From coarse to fine scale, or as the spatial extent of availability declined, fewer cover types were assigned as selected (i.e., proportional use > proportional availability), similar to McClean et al. (1998). Eight cover types were selected by deer under design 1 (landscape scale), while three and two cover types were selected by deer under design 2 (meso-scale) and each variant of design 3 (fine scale), respectively. Our landscape-scale definition of availability encom- 
TABLE 7. Cover selection by adult female White-tailed Deer $\left(n=20\right.$; design $3^{\text {a }}$ of Thomas and Taylor [1990]) pooled by agricultural growing season (150 days; 10 May-7 October; 23 home ranges during growing season, 25 home ranges during non-growing season) in an agro-forested landscape south-central Michigan, 2004-2006. Proportional use and selection indices were conditional on presence of cover type within home ranges.

\begin{tabular}{|c|c|c|c|c|c|c|}
\hline \multirow{2}{*}{$\begin{array}{l}\text { Season } \\
\text { Cover type }\end{array}$} & \multicolumn{2}{|c|}{ Proportional use } & \multicolumn{4}{|c|}{ Selection index ${ }^{\mathrm{b}}$} \\
\hline & $p$ & $\mathrm{SE}(p)$ & $I$ & $\mathrm{LCL}^{\mathrm{c}}$ & UCL & $\mathrm{Use}^{\mathrm{d}}$ \\
\hline \multicolumn{7}{|l|}{$\overline{\text { Growing }}$} \\
\hline Agriculture & 0.209 & 0.062 & -0.03 & -0.10 & 0.04 & o \\
\hline Conifer & 0.258 & 0.089 & 0.04 & -0.03 & 0.12 & o \\
\hline Herbaceous openland & 0.043 & 0.036 & 0.00 & -1.00 & 1.00 & o \\
\hline Lowland deciduous forest & 0.109 & 0.033 & 0.01 & -0.20 & 0.22 & o \\
\hline Lowland shrub & 0.230 & 0.044 & -0.04 & -0.09 & 0.02 & o \\
\hline Mixed wetland & 0.048 & 0.030 & 0.01 & -1.00 & 1.00 & o \\
\hline Northern hardwood & 0.041 & 0.012 & -0.20 & -0.65 & 0.26 & o \\
\hline Oak association & 0.028 & 0.009 & -0.08 & -1.00 & 1.00 & o \\
\hline Upland deciduous forest & 0.339 & 0.058 & 0.06 & 0.03 & 0.09 & + \\
\hline \multicolumn{7}{|l|}{ Upland shrub } \\
\hline Urban & 0.026 & 0.026 & 0.18 & -1.00 & 1.00 & o \\
\hline Water & 0.000 & & & & & \\
\hline \multicolumn{7}{|l|}{ Other } \\
\hline \multicolumn{7}{|l|}{ Non-growing } \\
\hline Agriculture & 0.183 & 0.041 & -0.03 & -0.09 & 0.03 & o \\
\hline Conifer & 0.228 & 0.067 & 0.08 & 0.02 & 0.14 & + \\
\hline Herbaceous openland & 0.013 & 0.009 & -0.38 & -1.00 & 1.00 & o \\
\hline Lowland deciduous forest & 0.091 & 0.030 & 0.01 & -0.20 & 0.21 & o \\
\hline Lowland shrub & 0.245 & 0.046 & 0.00 & -0.04 & 0.05 & o \\
\hline Mixed wetland & 0.029 & 0.014 & -0.22 & -1.00 & 0.64 & o \\
\hline Northern hardwood & 0.031 & 0.014 & -0.11 & -0.77 & 0.55 & o \\
\hline Oak association & 0.031 & 0.015 & 0.02 & -1.00 & 1.00 & o \\
\hline Upland deciduous forest & 0.294 & 0.046 & 0.02 & -0.01 & 0.05 & o \\
\hline \multicolumn{7}{|l|}{ Upland shrub } \\
\hline Urban & 0.00 & & & & & \\
\hline Water & 0.00 & & & & & \\
\hline Other & & & & & & \\
\hline
\end{tabular}

aDesign 3 use was based on proportion of locations in each cover type averaged over individuals; availability was based on mean proportion of area of cover types bounded by individual $95 \%$ fixed kernel home range by season. Cover types absent from a home range were not considered available to respective individuals.

bSelection indices based on Ivlev's (1961) electivity index (I).

${ }^{\mathrm{c}}$ Confidence limits $(95 \%)$ were truncated at -1 and 1 , and could not be estimated if proportional use $=0$.

${ }^{\mathrm{d}}$ If $95 \% \mathrm{CLs}>0$, selection (+) was assigned; if $95 \% \mathrm{CLs}<0$, avoidance (-) was assigned; \% CLs included 0, random use (o) was assigned.

passed the entire study area. Movements of individual radiomarked deer on our study area were limited to much smaller areas (i.e., a patchy distribution of deer) than the entire study area, suggesting that resource availability may have been overestimated.

Design 2 and design 3 (conditional and unconditional) seemed most appropriate to describe cover selection by deer in our study area, as selection was fairly consistent among designs. Considering our biological knowledge of White-tailed Deer, these designs supported our expectations of cover use by deer. For example, under design 2, conifers, lowland shrubs, and upland deciduous forests were selected regardless of season, perhaps as a result of the relative proximity of cover types. Under each variant of design 3 , conifers were selected during the non-growing season and upland deciduous forests were selected during the growing season.

Human perceptions of wildlife cover selection, as defined through use and availability, may also be affected by landscape characteristics. For example, landscape characteristics (e.g., patch size, shape, and distribution across a landscape) probably affect the distribution of wildlife species, such as White-tailed Deer, in a given area (Porter and Church 1987). The landscape matrix of our study area consisted of relatively few large patches (i.e., $>120$ ha) of agricultural areas, which probably were in excess quantity relative to the space-use needs of White-tailed Deer (Hiller et al. 2009). Consequently, at the landscape scale, un- 
known but perhaps large portions of the study were avoided or not used by deer.

\section{Conclusions}

We used use-availability data of White-tailed Deer to illustrate how and why a multi-scale approach (i.e., various methodological approaches describing use and availability) can be used to describe cover selection and increase our knowledge of deer ecology. If, for example, selection was considered only under design 1, the importance of lowland deciduous forest (Table 4) might be underestimated for White-tailed Deer. Similarly, the oak association cover type may show no difference in relative importance between seasons (under design 2), but the relative importance as defined through a multi-scale analysis could show a relatively large difference among spatial scales (Table 4) that may not otherwise be considered.

We suggest using multiple spatial scales when assessing resource selection, assuming appropriate useavailability data were collected. This should improve the interpretation of resource selection analyses through stronger evidence of selection or avoidance through a relatively comprehensive description of cover use. Specific research objectives, however, may not warrant the use of a multi-scale approach, such as a finescale study on screening cover at bedding sites used by White-tailed Deer. When the appropriate scale of study for an application is unknown, the relative importance of cover types across multiple scales should provide insight into cover selection, and therefore value of cover, for the wildlife species under study. Errors of assignment (e.g., effects of inappropriately defined resource availability) may also be minimized and overall selection patterns should emerge through such an approach.

\section{Acknowledgments}

We thank E. Arrow, B. Dodge, D. Haan, R. Havens, A. Leach, L. McNew, and M. Rubley for assistance with field data collection. We also thank M. Gore, G. Kuzyk, L. McNew, and one anonymous reviewer for providing comments that improved our manuscript. Logistical support was provided by B. Rudolph, S. Dubay, S. Hanna, R. Clute, V. Tisch, and F. Davis of the Michigan Department of Natural Resources. Financial contributors to this study included the Michigan Agricultural Experiment Station, Michigan State University, the Michigan Department of Natural Resources through the Federal Aid in Restoration Act under Pittman-Robertson project W-147-R, Safari Club International, and Whitetails Unlimited.

Documents Cited [marked * in text]

Madill, H., and W. Rustem. 2001. Michigan land resource project. Public Sector Consultants, Lansing, Michigan, USA. 125 pages.

Michigan Center for Geographic Information. 2001. IFMAP land-use, land-cover data. http://www.mcgi.state. mi.us/mgdl/?rel=ext\&action=sext. Accessed 28 July 2005. Michigan Department of Agriculture. 2002. Agricultural statistics: Jackson and Washtenaw Counties. http://www. michigan.gov/mda/. Accessed 16 August 2004.

Michigan Department of Natural Resources. 2005. 2005 deer population estimates for south central management unit. Michigan Department of Natural Resources, Wildlife Division Technical Report.

U.S. Census Bureau. 2003. 2000 census of population and housing, population and housing counts: Michigan. Washington, D.C., USA.

\section{Literature Cited}

Alldredge, J. R., and J. Griswold. 2006. Design and analysis of resource selection studies for categorical resource variables. Journal of Wildlife Management 70: 337-346.

Bender, L. C., and J. B. Haufler. 1994. A White-tailed Deer HSI for the Upper Great Lakes region. Pages 121-151 in Using an ecological classification system and wildlife habitat models in forest planning. By G. J. Roloff. Dissertation, Michigan State University, East Lansing, Michigan, USA.

Beyer, Jr., D. E., and J. B. Haufler. 1992. Diurnal versus 24-hour sampling of habitat use. Journal of Wildlife Management 58: 178-180.

Bodurtha, T. S., J. M. Peek, and J. L. Lauer. 1989. Mule Deer habitat use related to succession in a bunchgrass community. Journal of Wildlife Management 53: 314-319.

Braun, K. 1996. Ecological factors influencing White-tailed Deer damage to agricultural crops in northern lower Michigan. Thesis, Michigan State University, East Lansing, Michigan, USA.

Buskirk, S. W., and J. J. Millspaugh. 2006. Metrics for studies of resource selection. Journal of Wildlife Management 70: 358-366.

Clover, M. R. 1954. A portable deer trap and catch-net. California Fish and Game 40: 367-373.

Conner, L. M., and B. W. Plowman. 2001. Using Euclidean distances to assess nonrandom habitat use. Pages 275-290 in Radio tracking and animal populations. Edited by J. J. Millspaugh and J. M. Marzluff. Academic Press, San Diego, California, USA.

Garshelis, D. L. 2000. Delusions in habitat evaluation: measuring use, selection, and importance. Pages 111-164 in Research techniques in animal ecology: controversies and consequences. Edited by L. Boitani and T. K. Fuller. Columbia University Press, New York City, New York, USA.

Gladfelter, H. L. 1984. Midwest agricultural region. Pages 427-440 in White-tailed Deer ecology and management. Edited by L. K. Halls. Stackpole, Harrisburg, Pennsylvania, USA.

Guthery, F. S., A. R. Rybak, W. R. Walsh, S. D. Fuhlendorf, and T. L. Hiller. 2005. Quantifying usable space for wildlife with use-availability data. Journal of Wildlife Management 68: 655-663.

Harden, C.D., A. Woolf, and J. Roseberry. 2005. Influence of exurban development on hunting opportunity, hunter distribution, and harvest efficiency of White-tailed Deer. Wildlife Society Bulletin 33: 233-242.

Hiller, T. L., H. Campa III, and S. R. Winterstein. 2009. Estimation and implications of space use for White-tailed Deer management in southern Michigan. Journal of Wildlife Management 73: 201-209. 
Hobbs, N. T., and D. C. Bowden. 1982. Confidence intervals on food preference indices. Journal of Wildlife Management 46: 505-507.

Ivlev, V. S. 1961. Experimental ecology of the feeding of fishes. Yale University Press, New Haven, Connecticut, USA, 302 pages.

Johnson, D. H. 1980: The comparison of usage and availability measurements for evaluating resource preference. Ecology 61: 65-71.

Johnson, D. H. 1999. The insignificance of statistical significance testing. Journal of Wildlife Management 63: $763-772$.

Kie, J. G., and R. T. Bowyer. 1999. Sexual segregation in White-tailed Deer: density-dependent changes in use of space, habitat selection, and dietary niche. Journal of Mammalogy 80: 1004-1020.

Litvaitis, J. A., K. Titus, and E. M. Anderson. 1996. Measuring vertebrate use of terrestrial habitats and foods. Pages 254-274 in Research and management techniques for wildlife and habitats. Fifth edition. Edited by T. A. Bookout. The Wildlife Society, Bethesda, Maryland, USA.

Lopez, R. R., N. J. Silvy, R. N. Wilkins, P. A. Frank, M. J. Peterson, and M. N. Peterson. 2004. Habitat-use patterns of Florida Key Deer: implications of urban development. Journal of Wildlife Management 68: 900-908.

Main, M. B., F. W. Weckerly, and V. C. Bleich. 1996. Sexual segregation in ungulates: new directions for research. Journal of Mammalogy 77: 449-461.

Manly, B. F. J., L. L. McDonald, D. L. Thomas, T. L. McDonald, and W. P. Erickson. 2002. Resource selection by animals. Second edition. Kluwer Academic, Dordrecht, The Netherlands, 221 pages.

McClean, S. A., M. A. Rumble, R. M. King, and W. L. Baker. 1998. Evaluation of resource selection methods with different definitions of availability. Journal of Wildlife Management 62: 793-801.

Miranda, B. R., and W. F. Porter. 2003. Statewide habitat assessment for White-tailed Deer in Arkansas using satellite imagery. Wildlife Society Bulletin 31: 715-726.

Morrison, M. L., B. G. Marcot, and R. W. Mannan. 1992. Wildlife-habitat relationships: concepts and applications. University of Wisconsin Press, Madison, Wisconsin, USA, 343 pages.

Nams, V. O. 1989. Effects of radio-telemetry error on sample size and bias when testing for habitat selection. Canadian Journal of Zoology 67: 1631-1636.
Nams, V. O., and S. Boutin. 1991. What is wrong with error polygons? Journal of Wildlife Management 55: 172-176.

Otis, D. L. 1997. Analysis of habitat selection studies with multiple patches within cover types. Journal of Wildlife Management 61: 1016-1022.

Porter, W. F., and K. E. Church. 1987. Effects of environmental pattern on habitat preference analysis. Journal of Wildlife Management 51: 681-685.

Seaman, D. E., J. J. Millspaugh, B. J. Kernohan, G. C. Brundige, K. J. Raedeke, and R. A. Gitzen. 1999. Effects of sample size on kernel home range estimates. Journal of Wildlife Management 63: 739-747.

Severinghaus, C. W. 1949. Tooth development and wear as criteria of age in White-tailed Deer. Journal of Wildlife Management 13: 195-216.

Sommers, L. M. 1977. Atlas of Michigan. Michigan State University Press, East Lansing, Michigan, USA, 242 pages.

Stephens, D. W., and J. R. Krebs. 1986. Foraging theory. Princeton University Press, Princeton, New Jersey, USA, 262 pages.

Stewart, K. M., T. E. Fulbright, D. L. Drawe, and R. T. Bowyer. 2003. Sexual segregation in White-tailed Deer: responses to habitat manipulations. Wildlife Society Bulletin 31: 1210-1217.

Strauss, R. E. 1979. Reliability estimates for Ivlev's electivity index, the forage ratio, and a proposed linear index of food selection. Transactions of the American Fisheries Society 108: 344-352.

Thomas, D. L., and E. J. Taylor. 1990. Study designs and tests for comparing resource use and availability. Journal of Wildlife Management 54: 322-330.

Thomas, D. L., and E. J. Taylor. 2006. Study designs and tests for comparing resource use and availability II. Journal of Wildlife Management 70: 324-336.

White, G. C., and R. A. Garrott. 1990. Analysis of wildlife radio-tracking data. Academic Press, San Diego, California, USA, 383 pages.

Worton, B. J. 1989. Kernel methods for estimating the utilization distribution in home-range studies. Ecology 70: $164-168$

Worton, B. J. 1995. Using Monte Carlo simulation to evaluate kernel-based home range estimators. Journal of Wildlife Management 59: 794-800.

Received 31 December 2008

Accepted 16 June 2009 